Article

\title{
Lime Treatment of a Soft Sensitive Clay: A Sustainable Reuse Option
}

\author{
Marta Di Sante ${ }^{1, *(\mathbb{D})}$, Bruno Di Buò ${ }^{2}$, Evelina Fratalocchi ${ }^{1}$ and Tim Länsivaara ${ }^{2} \mathbb{C}$ \\ 1 Department of Materials, Environmental Sciences and Urban Planning, Università Politecnica delle Marche, \\ 60131 Ancona, Italy; e.fratalocchi@staff.univpm.it \\ 2 Faculty of Built Environment, Tampere University, 33014 Tampere, Finland; bruno.dibuo@tuni.fi (B.D.B.); \\ tim.lansivaara@tuni.fi (T.L.) \\ * Correspondence: m.disante@staff.univpm.it
}

Received: 16 March 2020; Accepted: 9 May 2020; Published: 14 May 2020

\begin{abstract}
This paper presents the results of research aimed at studying the hydraulic and mechanical behavior of Finnish soft clays treated by quicklime. This research investigated the effect of water content and curing time on the characteristics of the compacted soil treated with $7 \%$ lime, with the aim of verifying the effectiveness of lime treatment and evaluating its possible re-use, thus avoiding landfill disposal. A laboratory-testing program was carried out both on treated and untreated soil, supported by microstructural investigation. Results have shown a general increase of the hydraulic conductivity due to the addition of lime, reduction of compressibility, and increase in the soil shear strength for a wide range of water contents $(10 \%-40 \%)$, proving the effectiveness of the lime treatment. Lime addition to the compacted clay at high water contents (90\%-130\%) turned out to improve the mechanical characteristics to a lesser extent, while fractionated lime supply did not significantly improve the mechanical performance. The results of this research demonstrate that the re-use of sensitive clays, typically of high water contents, by lime addition require a drying process. Different drying procedures can be adopted (proposed in the paper) depending on the specific site conditions. However, the soil treatment is generally economically convenient in comparison to the disposal in waste landfills, which would represent the only alternative solution.
\end{abstract}

Keywords: Soil re-use; soft clay; lime stabilization; water content

\section{Introduction and Background}

The limited availability of natural good-quality soil to be used as construction material and the recent boost in finding environmentally sustainable solutions to engineering problems lead the geotechnical engineering community to study and finalize techniques to re-use excavated soils. As is widely known, mechanical and hydraulic properties of clayey soil can be improved by adding lime as a stabilizing agent in order to use the compacted lime-treated soil in earth constructions.

The lime stabilization technique offers both economic and environmental advantages when an excavated soil, suitable for lime treatment, is available on-site: there are no needs to supply good-quality soils from quarries and of landfill disposal of the in situ soil, as well as no environmental impact linked with transportation of soils (from quarry and to landfill).

Soft, sensitive clays are surely included among troublesome soils. Sensitive clay deposits are found along the coastal region of Scandinavia, Finland, as well as in Canada and in some regions of North Asia. The typical high compressibility, low undrained shear strength, and high sensitivity often make the geotechnical design rather challenging. Given their susceptibility to changes in consistency when worked or remoulded, they are usually excavated and landfilled. This paper has investigated 
finding re-use options for these soils as construction materials and the possibility of stabilizing them by adding lime.

\subsection{Soft, Sensitive Clays}

Clayey soils with a fragile structure that completely lose their undrained shear strength when remoulded are named sensitive clays. These clays can be assigned a degree of sensitivity, defined as the ratio between the undrained shear strength of an undisturbed specimen and the strength of the same specimen at the same water content but in a remolded condition [1-3]

High sensitivity is linked to depositional and post-depositional factors [1]. The main depositional factor is the inter-particle flocculation that creates an open micro-structure in such soils. Indeed, most of these clays were deposited in a salty marine environment (e.g., Norwegian marine clays), where the high concentration of salt ions reduced the repulsive forces between the soil particles, causing flocculation. Similar conditions can also occur in fresh water, in which high concentrations of calcium can be found. Among post depositional factors, the salt leaching is of major importance: after the uplift of clayey deposits caused by retreated glaciers, the pore water salinity decreased due to leaching of salts by rainfalls and fresh groundwater flow. The open flocculated structure was maintained but the repulsive forces between soil particles increased, resulting in a reduction of the liquid limit and very low-strength values when the material is remolded. Such sensitive clays with a very-low remolded shear strength $(\leq 0.4 \mathrm{kPa})$ are named quick clays, according to the classification by Rankka et al. [4].

As a consequence of different environmental depositional conditions, the soft, sensitive clay deposits located worldwide are characterized by different mineralogical and mechanical characteristics. For example, Finnish clays show high plasticity and clay content [5-7].

The origin of the Finnish clays is rather complex: fine-grained sediments originated in freshwater to brackish environment as a result of the different environmental stages that occurred during the Baltic Sea formation. The development of sensitivity in such clays is still under investigation as the salt leaching is not considered as the main factor $[7,8]$.

\subsection{Lime Stabilization}

Lime is a stabilizing agent capable of improving properties of fine-grained soils to obtain proper hydraulic and mechanical characteristics for earthen structures (e.g., dikes, road embankments) $[9,10]$. Lime stabilization is acknowledged as an environmentally sound and cost-effective application because costs of high-quality material from quarries and of disposal of the unsuitable in situ soil are eliminated, and therefore, it is widely applied worldwide.

The soil improvement by lime treatment is due to the sequence of chemical reactions that develop in the clayey soil-water-lime system. In particular, the immediate hydration of quicklime (highly exothermic) to form calcium hydroxide, $\mathrm{Ca}(\mathrm{OH})_{2}$, reduces the water content of the soil. The hydroxide dissociates in $\mathrm{Ca}^{++}$and $\mathrm{OH}^{-}$into the pore water of soil, and, consequently, cation exchange takes place, in which $\mathrm{Ca}^{++}$replaces existing cations of clay $\left(\mathrm{K}^{+}, \mathrm{Na}^{+}, \mathrm{H}^{+}\right.$, etc.). Mineral particles re-arrange in the flocculated/aggregated structure, giving rise to an intra-aggregate porosity and an apparent change in texture, with clay particles clumping together into larger-sized aggregates [11]. The above-described reactions are commonly identified as short-term reactions and they reduce the soil plasticity index (PI) and its water affinity $[12,13]$. The swelling potential decreases while hydraulic conductivity usually increases $[12,13]$. In the long-term, pozzolanic reactions develop between calcium ions and the silica or alumina of the lattices of clay minerals, improving strength and compressibility of the soil (e.g., References [14,15]).

Among the factors affecting soil-lime properties (e.g., type and amount of added lime, characteristics of the soil to be treated, curing time, and temperature), the soil natural water content strongly affects lime diffusion, timing, and mode of reactions with clay $[16,17]$. Therefore, the effectiveness of lime treatment must be investigated, especially in the case of soils characterized by high water contents, such as the Finnish sensitive clayey soil of concern. A proper design of soil-lime 
mixtures is based on a preliminary investigation of the soil to be used to verify its suitability to lime treatment. In addition, an extensive laboratory testing program should be carried out on the soil-lime mix in order to identify the best mix proportion, taking into account the specific in situ construction procedures and curing conditions [18]. Investigation of the microstructure of the compacted mixture can help in understanding reaction mechanisms for a proper analysis of the experimental results [19].

The aim of the present paper is to verify the effectiveness of quicklime treatment on a typical Finnish soft, sensitive, clayey soil in order to assess, at a laboratory scale, the feasibility of lime treatment for possible re-use of the soil, thus avoiding landfill disposal. A laboratory-testing program was carried out both on treated and untreated soil, supported by microstructural investigation.

\section{Materials and Methods}

The investigated soil comes from the so-called "dry crust" of the Finnish clays; that is, the fissured surface layer, subjected to weathering, of the over-consolidated Finnish clays [20]. Several samples were taken at a site close to the city of Kotka (region of Kymenlaakso, Finland), at a depth between 1.5 and $3.1 \mathrm{~m}$ from the ground surface.

The sensitivity of the soil samples was evaluated by means of the fall cone test, FCT [21], which provides a rapid and simple method for empirically determining the undrained shear strength of clays. It essentially consists in a cone placed on the surface of a sample and dropped under its own weight into the sample. The penetration is assumed to take place sufficiently rapidly for undrained conditions to apply. The undrained shear strength is given as a function of the weight, geometry, and depth of penetration of the cone into the sample [22,23]. The sensitivity is defined as the ratio of the shear strength measured on an undisturbed sample and the shear strength on the same sample once remolded at the same water content. The $30^{\circ}-100 \mathrm{~g}$ cone was used in testing all the undisturbed samples of the Finnish soil, whereas the $60^{\circ}-10 \mathrm{~g}$ cone was used for the respective remolded ones [21].

After sensitivity determinations, all the samples were thoroughly mixed in the laboratory to obtain a uniform reconstituted soil for testing.

Classification tests were performed on the soil (grain size distribution: ASTM D422-07; liquid limit: CEN ISO/TS17892-12; plasticity index: ASTM D4318-05) together with measurements of its specific gravity (ASTM D854-14). Energy Dispersive X-Ray Spectroscopy (EDS, PHOENIX, ECON IV detector, EDAX Inc., NJ, USA) allowed for identifying the soil chemical composition. In particular, we evaluated the amount of sulphate and of organic matter (ASTM D2974-07) to verify the soil suitability for lime treatment according to the requirements by UNI EN 14227-11: 2006.

We investigated the clay fraction of the soil to determine its cation exchange capacity and surface area (CUR n.33 EUBA 2002), as well as mineralogical composition, by X-Ray diffraction (Philips diffractometer, PW1730 X-ray generator, PW 1050/70 goniometer and CuK radiation).

The type of lime used for the soil treatment is a fine calcic quicklime, classified as CL80-Q dp (UNI EN 459-1). The choice of a quicklime is due to its greater effectiveness than hydrated lime, content being equal, in improving short- and long-term performance of fine-grained soils.

The initial consumption of quicklime (ICL) for the soil investigated, needed as the minimum lime percentage to start pozzolanic reactions with a soil, was determined by the standard procedure ASTM C977-00. We selected the lime content of $7 \%$ by dry mass of soil based on the criteria discussed in Section 3.1.

All the soil-lime specimens were prepared according to the following steps:

1. The air-dried soil was crumbled (to $2 \mathrm{~mm}$ in size),

2. The amount of tap water necessary for the desired moisture content was added to the soil,

3. Wait at least $24 \mathrm{~h}$ after water addition to allow a uniform hydration,

4. Lime and soil were mixed in wet state (as usually done in the field, e.g., Reference [18]) until a uniform distribution was achieved, 
5. The soil-lime mixture was immediately compacted according to the Standard Proctor procedure (ASTM D698-12) in three layers, obtaining samples of $101 \mathrm{~mm}$ in diameter and $116.5 \mathrm{~mm}$ in height,

6. The samples were trimmed to take specimens with the proper dimensions for each geotechnical test to be performed.

All the specimens were cured in sealed envelopes at a controlled temperature of $20 \pm 2{ }^{\circ} \mathrm{C}$ until testing. The only exception was the specimens from soil at the natural water content $\left(w_{\mathrm{Nat}}\right)$, for which steps 1 and 2 were not necessary.

No significant variations in the water contents of samples were measured after curing (no condensation was indeed found in the envelopes).

Microstructural and chemical investigations were performed by SEM observations carried out with the FESEM SUPRA 40-ZEISS, Germany (source: Schottky field output-FEG, detector Everhart-Thornley for secondary electrons, 4 sectors solid-state detector for backscattered electrons, maximum voltage: $30 \mathrm{kV}$ ) and by a XL20 Microscope-Philips, Nederland (W filament, detector Everhart-Thornley for secondary electrons, solid-state detector for backscattered electrons, maximum voltage: $30 \mathrm{kV}$ ). Observations were carried out after air dewatering of samples and their gilding by means of a K550 sputter coater-Emitech, Italy. Compacted soil and soil-lime samples at the optimum water content ( $\mathrm{w}_{\mathrm{OPT}}$ ) were observed and analyzed at 2, 7, and 28 days of curing times by EDS (Quantax 200-Z10 X-ray microanalysis system-Bruker, MA, USA, with Silicon Drift Detector without liquid nitrogen, 20-30 kV voltage). We used observations and chemical analyses to discuss the geotechnical test results.

We performed the following geotechnical tests on specimens at different water contents, both on the compacted untreated soil and on compacted soil-lime mixtures in order to assess improvements induced by lime treatment:

- Hydraulic conductivity tests in flexible walls permeameters, with tap water as a permeant (ASTM D5084-10): the effective confining pressure of $35 \mathrm{kPa}$ was applied to simulate stress levels in surficial layers.

- Incremental load one-dimensional consolidation tests (ASTM D2435-04) on soil-lime specimens (50 $\mathrm{mm}$ in diameter and $19 \mathrm{~mm}$ in height) after 7 and 28 days of curing.

- $\quad$ Direct shear tests (DS-ASTM D3080-98) at 28 days of curing with a very low relative horizontal displacement rate $(0.0024 \mathrm{~mm} / \mathrm{min})$ in the range of vertical effective stresses of $20-100 \mathrm{kPa}$.

The hydraulic conductivity tests, direct shear tests, and consolidation tests were performed (as specified in the relevant standards) on saturated specimens.

The aforementioned testing program was planned as a general screening of the efficiency of the lime treatment in improving the mechanical performance of the soil and influencing the hydraulic performance. A more sophisticated testing program will be performed on the basis of the results of this screening phase, to properly characterize the mechanical behavior of the lime-treated soil, taking into account suction effect when of concern (e.g., for water contents close to the optimum one) and environmental factors potentially affecting the soil-lime mechanical characteristics (e.g., freeze-thaw cycles, dry-wet cycles).

\section{Results and Discussion}

\subsection{Soil Classification and Physical-Chemical Characterization}

The sensitivity index measured on all the taken samples resulted to be in the range of 15-40. Therefore, the soil can be classified as a medium-high sensitive clay [4]. The natural water content $\left(\mathrm{w}_{\mathrm{Nat}}\right)$ of the undisturbed samples resulted in the range of $80 \%-130 \%$.

The geotechnical properties of the uniform reconstituted soil are summarized in Table 1. According the Unified Soil Classification System (USCS), the soil is an elastic silt (MH). 
Table 1. Soil Characteristics.

\begin{tabular}{cc}
\hline Property & Value \\
\hline Particle size & \\
Sand $(\%)$ & 2 \\
Fine $(\%)$ & 98 \\
Clay $(<2 \mu \mathrm{m}, \%)$ & 45 \\
Consistency Limits & \\
Liquid Limit $(\%)$ & 80 \\
Plasticity Index $(\%)$ & 38 \\
Organic matter $(\%)$ & 3.8 \\
Specific gravity (-) & 2.67 \\
Cation Exchange Capacity (meq/100 g) & 14.9 \\
Specific surface (m $\left.{ }^{2} / \mathrm{g}\right)$ & 115.8 \\
Initial Consumption of Quicklime $(\%)$ & 3.3 \\
\hline
\end{tabular}

Based on the fine percentage, plasticity index, and organic matter (Table 1), and on the amount of sulphate $(0.014 \%$ by dry mass of soil), the soil fully matches the suitability requirements for lime treatment (UNI EN 14227-11: 2006).

The mineralogical components of the clay fraction resulted to be mainly Mica, Chlorite, and Quartz, and Amphibole and Albite were also detected (Figure 1). Energy Dispersive X-Ray Spectroscopy highlighted the presence of the chemical elements listed in Table 2.

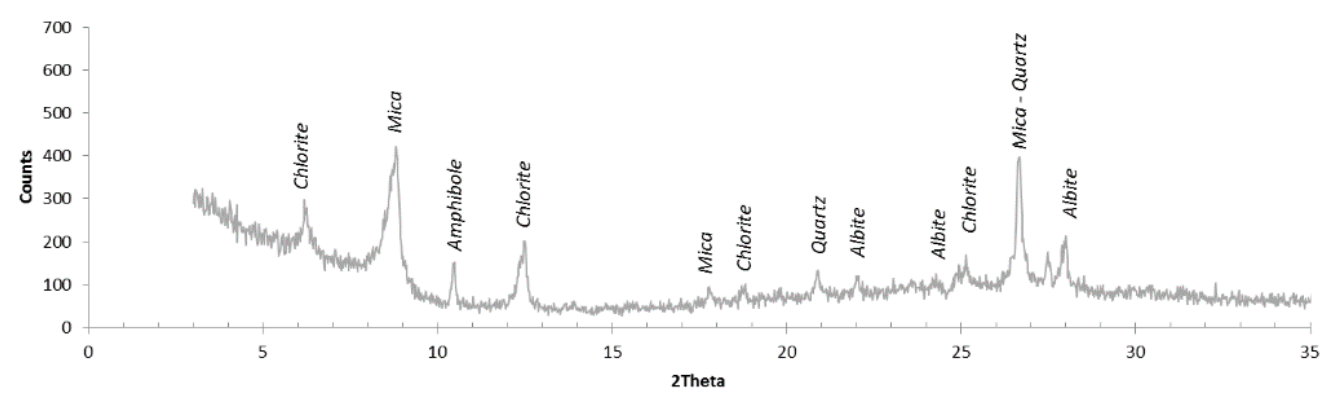

Figure 1. X-Ray Diffraction pattern of the clay fraction of soil.

Table 2. Soil chemical composition.

\begin{tabular}{cc}
\hline Element & Mass (\%) \\
\hline Silicon & 52 \\
Calcium & 2 \\
Aluminium & 15 \\
Iron & 16 \\
Potassium & 7 \\
Magnesium & 3 \\
Sodium & 2 \\
Titanium & 1 \\
\hline
\end{tabular}

\subsection{Selection of Lime Amount and Compaction Parameters}

For lime-stabilized soils, the first criterion to identify the optimum lime amount is the evaluation of the ICL value (Table 1), that is the minimum lime percentage to start pozzolanic reactions and, therefore, the lowest content of lime to be considered. However, a lime percentage equal to ICL $+1 \%-2 \%$ is typically investigated when designing lime-treated soils as the minimum one to ensure the development of long-term (i.e., pozzolanic) reactions, considering the variation in the chemical composition of a natural material such as a soil. The second followed criterion is not commonly considered in the conventional practice but was conceived for the specific soil of concern: the treatment 
effectiveness can be negatively influenced by the very high natural water content and, therefore, the ability of quicklime to reduce the water content, w, should be investigated in such case. To this end, different amounts of lime were added to the soil at $w_{\text {Nat }}$ and the reduction of water content after lime addition was measured. Figure 2 shows the water content reduction as a function of the amount of lime added. The amount of $7 \%$ of quicklime turned out to be a good compromise between costs and advantages in terms of drying effects and workability. Workability was assessed by visual inspection: friable clods of the soil-lime mixture (image in Figure 2) did not show any loss of consistency when manually remolded. In the present research phase, $7 \%$ was selected as the minimum amount of lime to be investigated in the geotechnical experimental program.

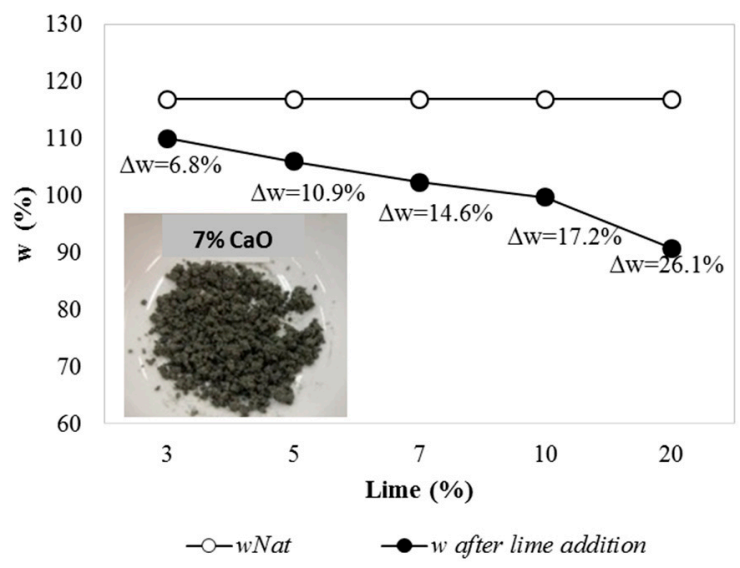

Figure 2. Water content reduction as a function of lime amount. $(\Delta \mathrm{w}=$ natural soil water content-water content after lime addition). The image shows the features of the soil after the addition of $7 \%$ quicklime.

The compaction curves of the untreated soil and of soil $+7 \%$ quicklime are shown in Figure $3 a$. A significant reduction of the optimum water content and a negligible difference in the maximum dry unit weight, $\gamma_{\mathrm{dmax}}$ (equal to $12.0 \mathrm{kN} / \mathrm{m}^{3}$ ), are observed after the treatment, as typically occurs for lime-treated soils [24]. It is worth noting the very low value of the $\gamma_{\mathrm{dmax}}$, for both the treated and the untreated soil. The range of water contents which guarantees a dry unit weight higher than $95 \%$ of the $\gamma_{\mathrm{dmax}}$ (as most of technical specifications require for construction works) is $10 \%-40 \%$.

The reduction in water content due to lime treatment for all the compacted samples of the present experimental work is shown in Figure $3 b$, where $\Delta w$, calculated as the difference between w before $\left(w_{\text {pre }}\right)$ and after lime addition $\left(w_{\text {post }}\right)$, is plotted against the initial water content $\left(w_{\text {pre }}\right)$. Results show that the higher the initial $\mathrm{w}$, the higher the reduction in $\mathrm{w}$ expectable with the binder addition.
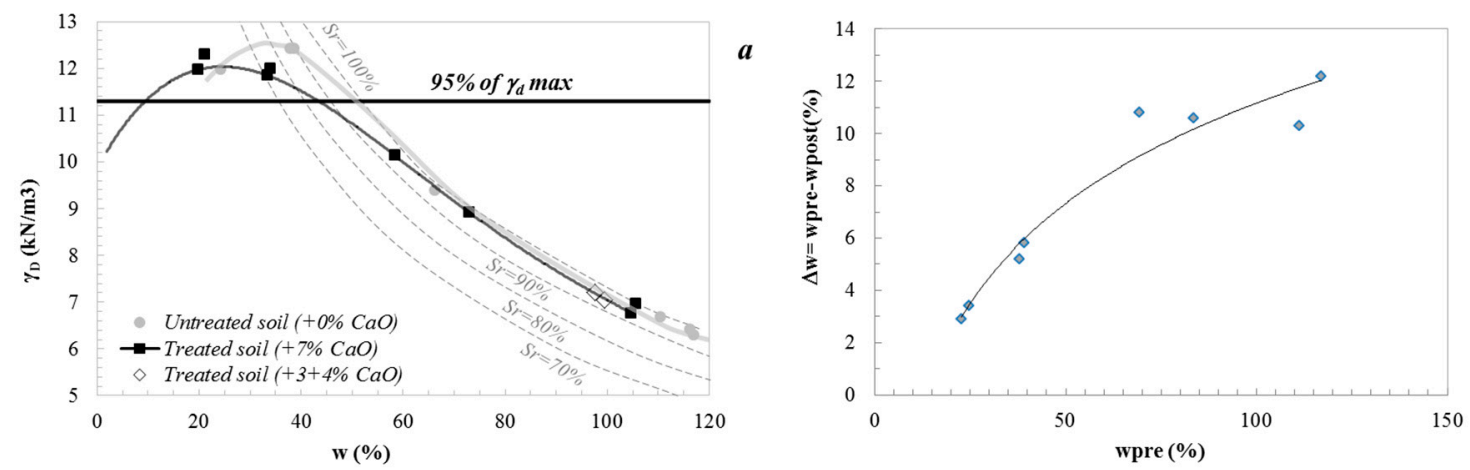

Figure 3. Compaction curves (standard effort) of (a) the treated and untreated soil ( $\mathrm{Sr}=$ degree of saturation) and (b) water content reduction for treated compacted samples.

It is fundamental to point out that, after lime treatment and compaction, the material lost its sensitive behavior, showing no more fluid consistency when remolded. 


\subsection{Microstructural and Chemical Investigation}

Micrographs of the untreated soil are shown in Figure 4. The main constituents of the clay fraction, resulted in the X-Ray diffraction (Section 3.1, Figure 1), are evident in SEM images. The observed samples are mainly constituted by mica (marked with $\mathrm{M}$ in Figure 4). Rosette-like structures of chlorite (ChL) are widely distributed across the samples, amphibole (A in Figure 4c) and plagioclase (PL in Figure 4a) are detected, too. Euhedral pyritic grains (Py in Figure 4d) are sporadically present, as highlighted by the presence of Sulfur and Iron as the only constituents (EDS performed on the crystals). Diatoms are systematically detected in the observed samples ( $\mathrm{D}$ in Figure 4b,e,f): they are centric diatoms, also observed in freshwater environments. Their presence confirms the depositional history of Finnish fine-grained soils (described in Reference [25]), whose initial sedimentation occurred in the Baltic Ice Lake phase of the Baltic sea development during Pleistocene. The lake originated from accumulation of freshwater after the melting of the North glacier.
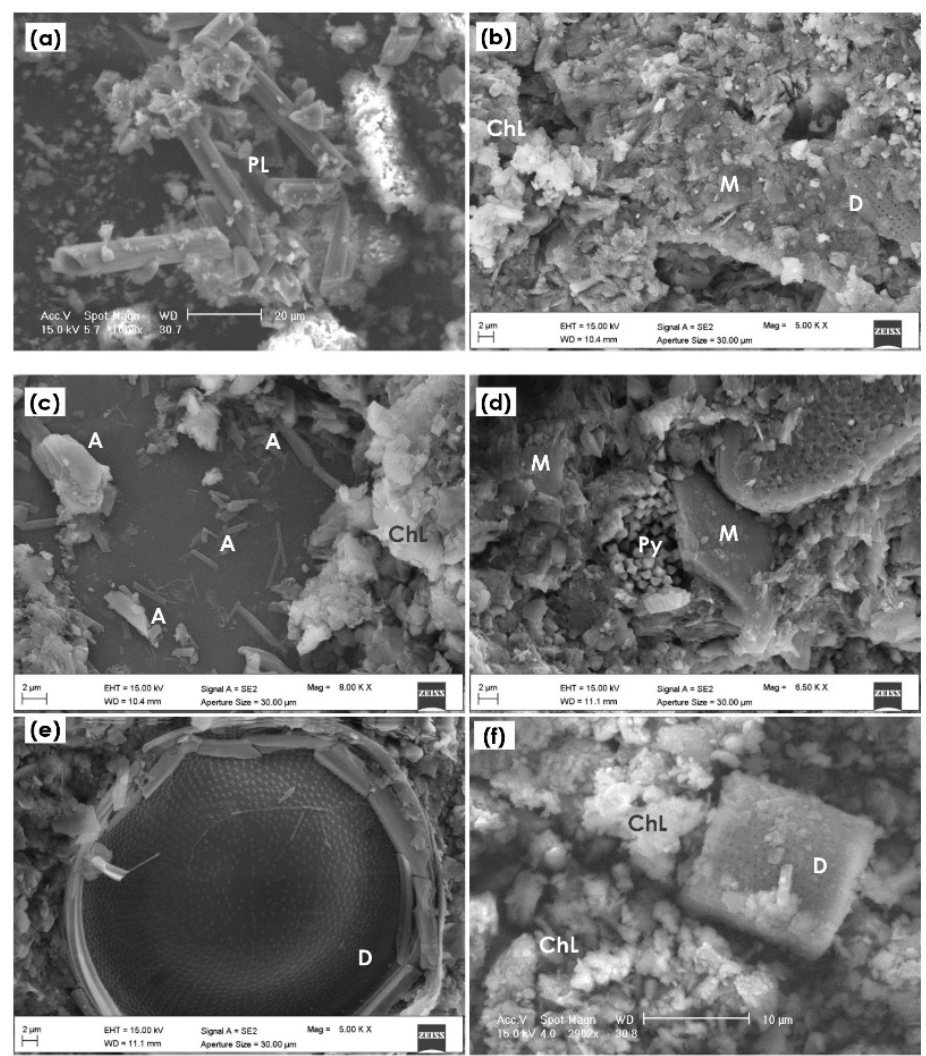

Figure 4. SEM images of the untreated soil: $\mathrm{PL}=$ Plagioclase $(\mathbf{a}), \mathrm{ChL}=$ Chlorite $(\mathbf{b}, \mathbf{c}, \mathbf{f}), \mathrm{M}=$ Mica $(\mathbf{b}, \mathbf{d})$, $\mathrm{D}=$ Diatoms $(\mathbf{b}, \mathbf{e}, \mathbf{f}), \mathrm{A}=$ Amphibole $(\mathbf{c})$, Py = Pyrite $(\mathbf{d})$.

The change in the soil appearance after lime addition is shown in Figure 5, in which SEM images of soil-lime samples, compacted at the optimum water content $(\mathrm{w}=33 \%)$ are displayed at 2 days of curing (Figure 5b), 7 days (Figure 5c,d), and 28 days (Figure 5f). The change in texture with aggregates of clay particles and large pores is detectable in Figure 5 (pores pointed with white arrows). The samples have a spongy appearance with acicular crystalline structures often covering the aggregates. This highly porous nature of the treated soil may lead to the lowered dry unit weight registered for the treated samples (Figure 3a).

Early pozzolanic products are detectable at 2 days of curing (Figure 5a,b), turning out to be uniformly distributed across the entire sample. We detected two different morphologies of reaction products in the treated samples: calcium silicate hydrate $(\mathrm{CSH})$ in a gel form that coats particles causing the spongy appearance and CSH in crystal form (acicular structures). The growth of crystalline 
pozzolanic products continues with the curing of sample (7 and 28 days in Figure $5 c, d, e, f$, respectively) with acicular structures that reach $10 \mu \mathrm{m}$ in length at 28 days. EDS performed on pozzolanic products (area in the white rectangle in Figure 5a) confirmed the presence of Calcium and Silicon as main elements.
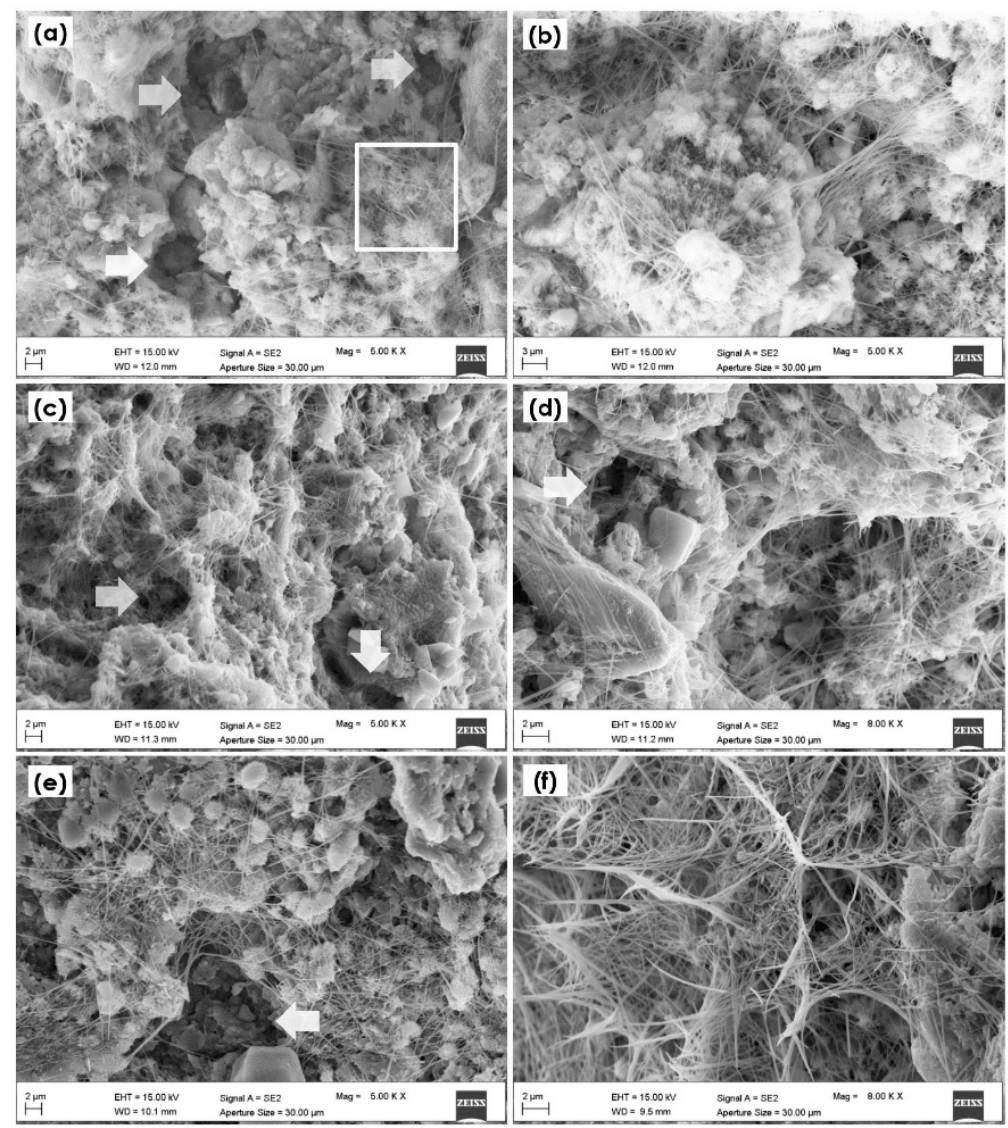

Figure 5. SEM images of soil treated with $7 \% \mathrm{CaO}$, compacted at optimum water content after (a,b) 2 days of curing, (c,d) 7 days of curing, and (e,f) 28 days of curing.

Besides the previously described reaction products, we detected other crystalline structures in the treated samples (Figure 6): with the help of EDS, they were identified as scalenohedral (Figure 6a) and cubic (Figure 6b) precipitated calcium carbonate, as calcium, carbon, and oxygen were the only detected elements. The occurrence of calcium carbonate precipitation is likely to happen given the amount of lime added (7\%) that is far higher than the ICL (3.3\%). The calcium exceeding the quantity necessary for the development of soil-lime reactions could probably have been involved in a carbonation reaction: when compacting at $\mathrm{w}=33 \%$, samples are unsaturated (saturation line in Figure 3a) and air in soil pores can be responsible for the observed precipitates. 

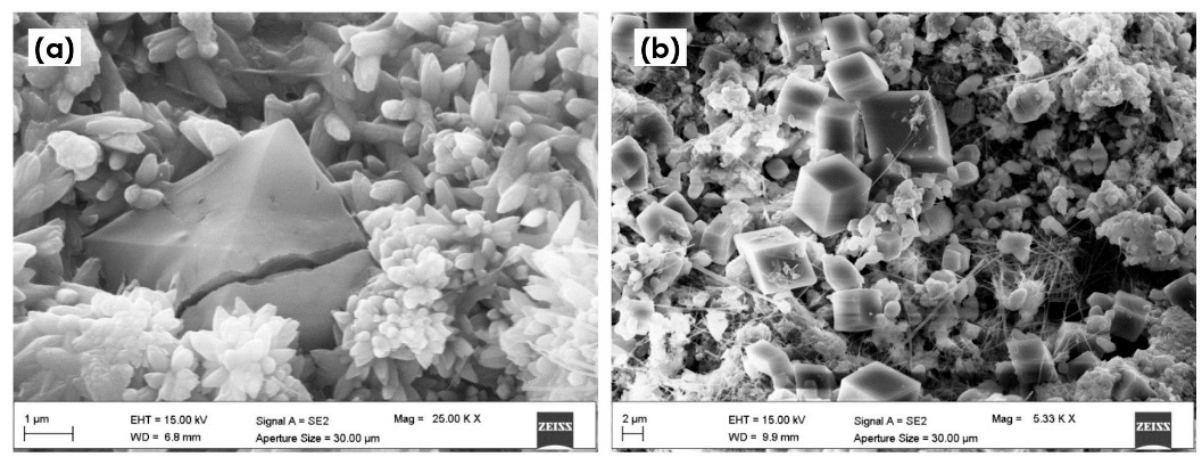

Figure 6. SEM images of precipitated octahedral calcium carbonate (a) and cubic calcium carbonate (b) in soil treated with $7 \% \mathrm{CaO}$, compacted at optimum water content.

\subsection{Hydraulic Conductivity}

Figure 7 shows the compaction curves of the untreated and treated soil together with the hydraulic conductivity values measured on most of the compacted samples as a function of the water content. When hydraulic behavior of the lime-treated clay is considered, two main factors have to be taken into account: the molding water content and the curing time. By plotting the long-term hydraulic conductivity values (steady $\mathrm{k}$ values at curing of 30-60 days) against molding water contents (Figure 7), it is possible to state that there is a general increase in hydraulic conductivity due to lime addition and that an increase in the molding water content, $\mathrm{w}$, causes a significant reduction ( 2 orders of magnitude) in the long-term k-values. The major increase, from $2.6 \times 10^{-9} \mathrm{~m} / \mathrm{s}$ to $3.0 \cdot \times 10^{-7} \mathrm{~m} / \mathrm{s}$, is registered for $\mathrm{w}$ $=35 \%$, included in the optimum water content range. Such finding, typical for lime-treated soils [26], is justified by the observed open microstructure (Figure 5) caused by the aggregation of clay particles due to lime addition. Compaction water contents next to the natural values ( $w_{\text {Nat }}=80 \%-130 \%$ ) could compromise the draining capability acquirable with treatment. In this case, cation exchange reaction is probably not sufficient to create the flocculated structure and particles remain in an oriented, laminated state, due to the high amount of water.

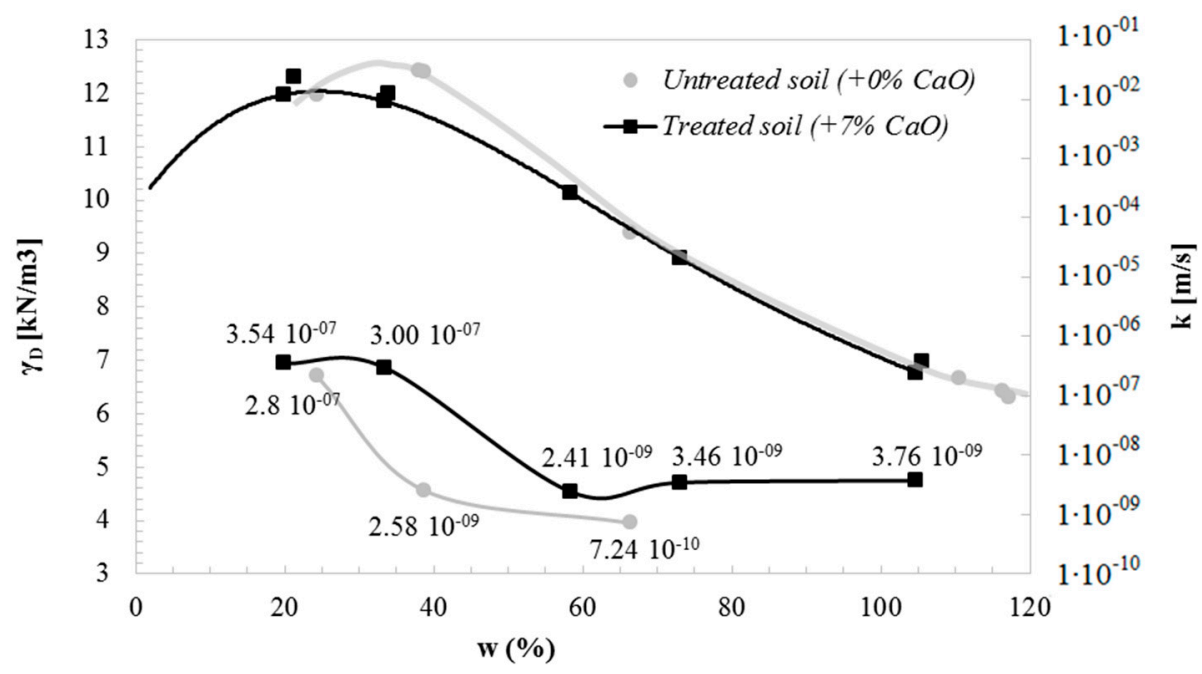

Figure 7. Moisture-dry unit weight relationship, Proctor plane (left y-axis), and long-term permeability values (right y-axis) for untreated compacted soil and for soil treated with $7 \% \mathrm{CaO}$.

Referring to the curing time effects, in Figure 8, it is possible to observe the decreasing trend of $\mathrm{k}$ values for a lime-treated sample compacted at the optimum conditions in a very long-term test (up to 7 months). Starting from 7 days of curing $\left(\mathrm{k}=6 \times 10^{-7} \mathrm{~m} / \mathrm{s}\right)$, the hydraulic conductivity reduction is significant until about 4 months of curing, reaching $2 \times 10^{-7} \mathrm{~m} / \mathrm{s}$. The reduction is due to the growth of pozzolanic products in gel form (Figure 5) capable of partially filling the inter-aggregate porosity [27]. 
In the long-term (i.e., more than 120 days of curing), hydraulic conductivity held steady, marking the end of the pozzolanic reaction in the tested sample.

On the contrary, the hydraulic conductivity trends with curing time of the lime-treated samples compacted wet of optimum ( $w>55 \%$, Figure 8 ) show no reductions. This corroborates the hypothesis that the effects of high water contents on hydraulic conductivity prevail on soil-lime reaction effects, even increasing the curing time.

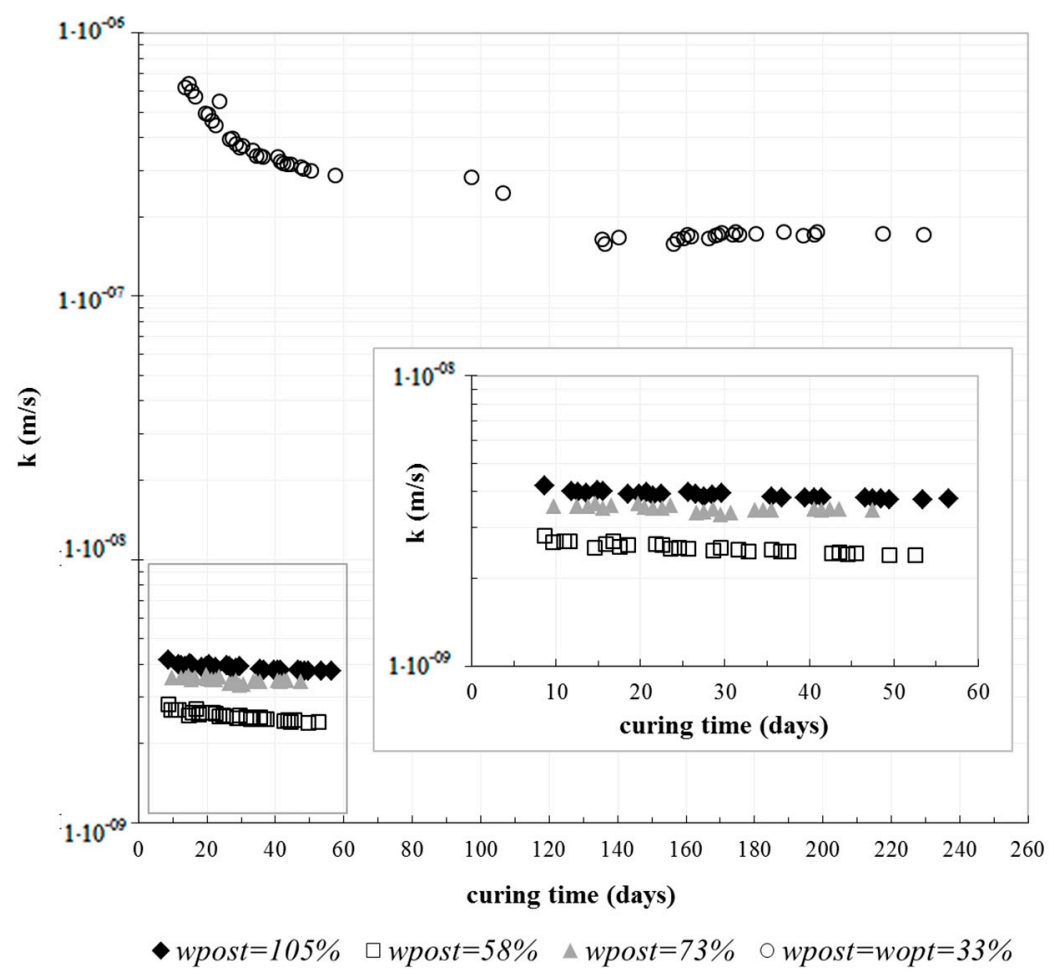

Figure 8. Hydraulic conductivity of soil treated with $7 \% \mathrm{CaO}$ as a function of curing time. Very long-term test on the specimen compacted at $\mathrm{w}=33 \%$ and tests on specimens compacted at $\mathrm{w}>55 \%$, i.e., wet of optimum.

\subsection{Compressibility}

Figure 9 shows the results of the one-dimensional compression tests performed at 7 and 28 days of curing on specimens of different water contents; for each of the compressibility curves of the treated samples, the corresponding position in the Proctor plane is shown. The compression curve of the compacted, untreated soil at $w=100 \%$ (closed to $w_{N a t}$ ) is also displayed in Figure $9 a$, where the significant reduction in compressibility caused by lime treatment can be immediately noticed.

In particular, at the effective vertical stress of $50 \mathrm{kPa}$ (typical value for designing of road embankments), axial deformation is reduced by $80 \%$. Such an improvement in compressibility for the lime-treated specimens at the natural water content is not enough since high deformability residues $(4 \%)$ and no further improvements are obtained with curing (i.e., compressibility curve for 7 and 28 days of curing are definitely similar).

The compressibility curves for specimens at lower molding water contents are shown in Figure $9 \mathrm{~b}, \mathrm{c}$. The deformability tends to decrease for increasing dry density. Referring to optimum conditions (Figure 9c), significant improvements in compressibility can be obtained after 28 days of curing if compared with the 7 days results. In particular, up to $400 \mathrm{kPa}$ of effective vertical stress, very low compressibility is found for the specimen tested after 28 days of curing.

The strain behavior of the soil-lime mixtures, similar to that of over-consolidated soils with a typical yielding stress, can be attributed to the cementation induced by pozzolanic reactions that are able to create a more rigid structure also under high pressures. In specimens with high water contents 
(i.e., $>55 \%$ ), the attained reduction in compressibility is lower and no improvements are observed between 7 and 28 days of curing. However, low deformations in the range of pressure typical of earthworks (e.g., road embankments, dams) are guaranteed when soil-lime mixtures were compacted at water contents of about $30 \%$.

$a$

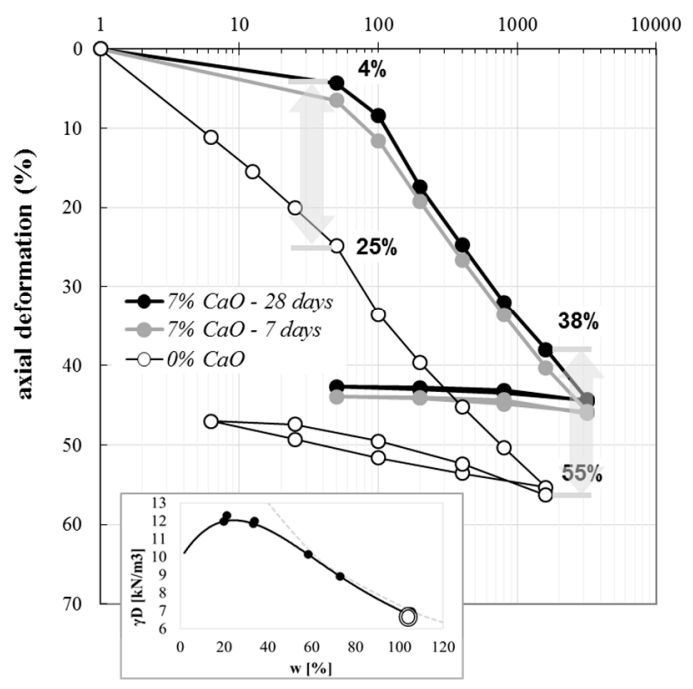

$c$

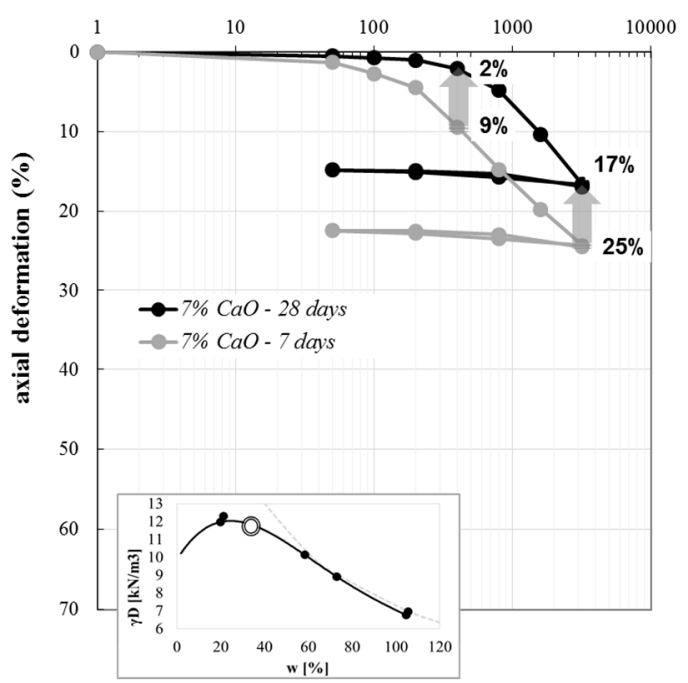

$b$ effective vertical stress $(\mathrm{kPa})$

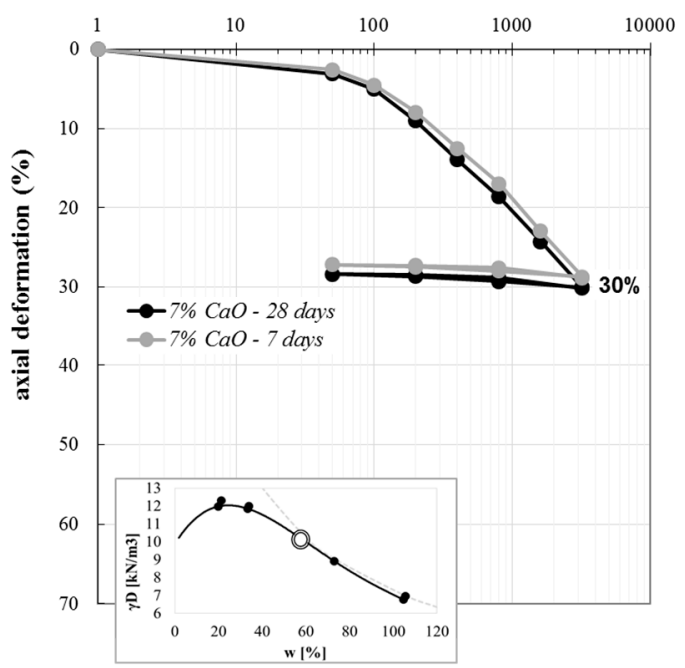

Figure 9. Compressibility curves of soil treated with $7 \% \mathrm{CaO}$, at 7 and 28 days of curing, compacted at different water content: (a) natural water content, (b) $\mathrm{w}=58 \%$, i.e., wet of optimum, and (c) optimum water content. In figure (a), the compressibility curve of the untreated compacted specimen is also plotted.

\subsection{Shear Strength}

As a preliminary evaluation of possible increase in the shear strength of the clay by lime addition, we carried out direct shear tests at 28 days of curing on specimens compacted at different water contents. Drained conditions were ensured for all the tested specimens by applying a very low relative horizontal displacement rate $(0.0024 \mathrm{~mm} / \mathrm{min}$, the time to failure is three times higher than those suggested by ASTM D3080-98, proving the drained conditions). We carried out tests on treated and untreated specimens compacted at the natural water content and at the relevant optimum conditions. 
In the latter case, the observed high hydraulic conductivity value (see Figures 7 and 8 a) was a further reassurance of failure in drained conditions.

Before discussing the shear strength parameters, it is important to point out the peculiar behavior of the soil-lime mixture, i.e., artificial materials characterized by a soil fabric resulting from chemical reactions. As discussed in Section 1.2, aggregation causes an apparent modification in grain size distribution, switching from clayey soil into a coarse, cemented, grained material.

Figure 10 shows the shear stress-displacement curves and the related variation in volume of specimens of the natural and treated soil compacted at $\mathrm{w}=\mathrm{w}_{\mathrm{Nat}}$ and at $\mathrm{w}=\mathrm{w}_{\mathrm{OPT}}$, after consolidation under the confining stress of $100 \mathrm{kPa}$.

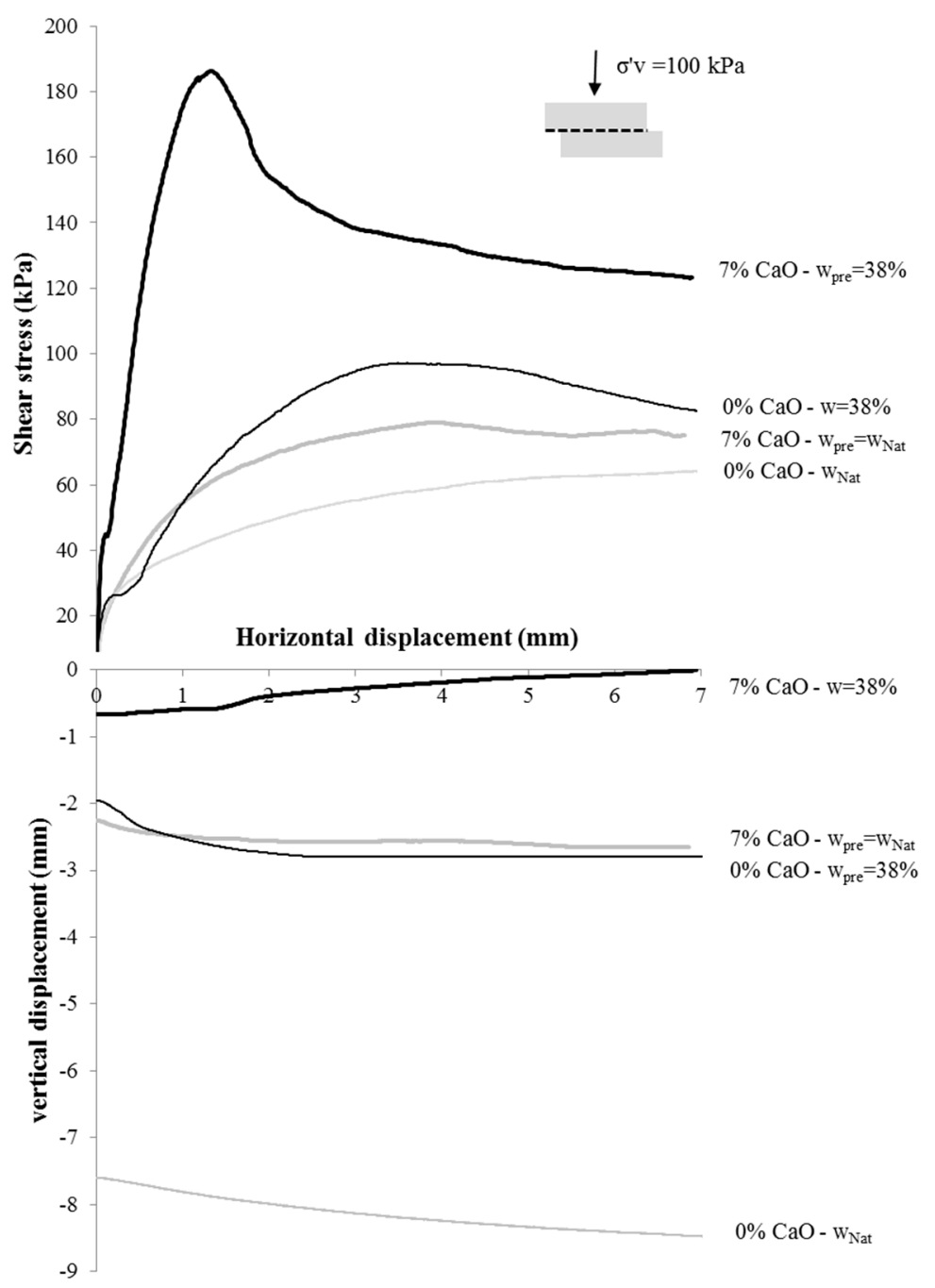

Figure 10. Stress-displacements curves and volume changes, obtained from direct shear tests, for specimens of treated $(7 \% \mathrm{CaO})$ and untreated soil compacted at different water content; vertical confining pressure $=100 \mathrm{kPa}$.

At the natural water content, the 7\% lime addition does not significantly alter the stress-strain behavior of the clay, which still performs as a weak strain hardening material. We obtained similar results on the specimen consolidated under effective confining pressure of $50 \mathrm{kPa}$ and $150 \mathrm{kPa}$. The tests confirm the significant reduction in compressibility due to lime addition and shows that the shear strength is appreciably increased. At very low w, close to the $\mathrm{w}_{\mathrm{OPT}}$, the compacted natural clay shows the typical behavior of compacted fine-grained soil, with a slightly brittle behavior. The corresponding treated sample exhibits a great increase both in the shear stiffness and in the peak shear strength, which are typical of lime-stabilized soils. 
The Mohr Coulomb failure envelope was found to fit the data well in the range of the applied vertical stresses (Table 3 and Figure 11). The very low cohesion, $c^{\prime}$, for treated and untreated samples at the natural water content confirms the predominant effect of the water content on the shear strength, with negligible cementing contribution of the lime addition. The increased peak shear strength angle, $\Phi^{\prime}$, of the treated sample can be explained considering the predominant effect of lime addition in modifying the apparent grain size distribution of the clay, since a shear angle of $37^{\circ}$ is typical of coarse soils.

For lower water content (close to the $\mathrm{w}_{\mathrm{OPT}}$ ), the effect of lime as a binder is evident both in terms of cohesion and peak shear angle, proving the effectiveness of the lime addition as a cementing agent, too. Proper tests are necessary to investigate the different mechanical performance as a function of the water content at a deeper level; however, as for compressibility, the low shear strength due to the high natural water content seems not to be sufficiently improvable by lime addition.

Table 3. Shear strength parameters of the treated and untreated soil compacted at different water contents.

\begin{tabular}{ccccc}
\hline Lime (\%) & $\mathbf{w}_{\text {pre }}(\mathbf{\%})$ & $\mathbf{w}_{\text {post }}(\mathbf{\%})$ & $\mathbf{c}^{\prime} \mathbf{( k P a )}$ & $\boldsymbol{\Phi}_{\mathbf{p}}{ }^{\prime}\left({ }^{\circ}\right)$ \\
\hline 0 & 115 & - & 2 & 32 \\
0 & 38 & - & 7 & 38 \\
7 & 111 & 101 & 2.5 & 37 \\
7 & 38 & 32 & 13 & $60{ }^{*}$ \\
\hline
\end{tabular}

* values to be intended as model shear resistance angles, as discussed in the text.

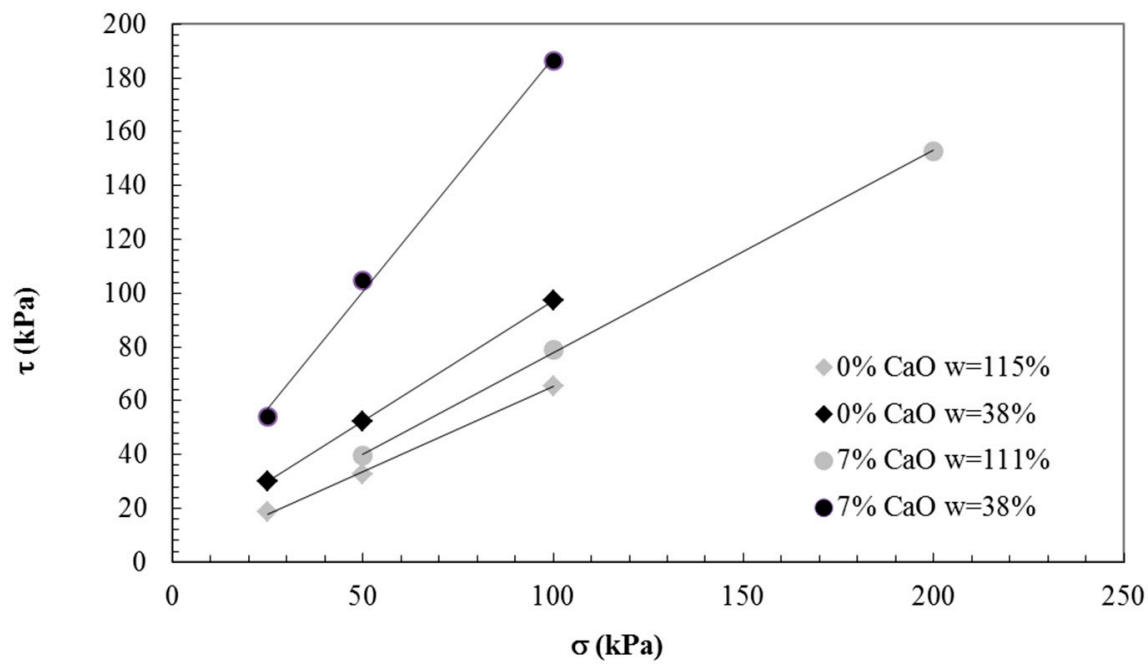

Figure 11. Mohr-Coulomb peak failure envelopes obtained from direct shear tests, for specimens of treated $(7 \% \mathrm{CaO})$ and untreated soil compacted at different water contents.

\subsection{Lime Addition in Multiple Steps}

The results obtained for the specimens compacted at the natural water content highlighted that a high compaction w can undermine the improvement of lime treatment.

We explored the possibility of adding the selected lime amount in two steps, allowing a mellowing period of $24 \mathrm{~h}$ between them, to try to overcome problems related to the high natural water content. In particular, the first addition was 3\% CaO and the second was $4 \%$. The mellowing is supposed to cause a further improvement of the workability due to the development of primary reaction products during the $24 \mathrm{~h}$ spent at loose state and to a higher drying effect during mixing with lime. The latter effect is caused by the heat developed by quicklime hydration (highly exothermic reaction) that is repeated twice with the two steps of lime addition. 
For the two Proctor samples prepared (see empty diamonds in Figure 3a), the compaction w was equal to $99.5 \%$ and $97.6 \%$, starting from an initial water content of $114 \%$ (the natural water content). The obtained mean reduction of $15.4 \%$ is higher than the reduction obtained compacting the soil after a unique supply of quicklime, which causes an 11\% reduction (Figure 3b). Anyway, the difference was not sufficiently high for an effective improvement in the workability.

The hydraulic conductivity obtained splitting up the binder addition was $4 \times 10^{-9} \mathrm{~m} / \mathrm{s}$, with a steady trend from 7 to 60 days of curing. This proves that the multiple step addition was not effective in modifying the overall hydraulic performance.

Moreover, we found no improvement when supplying lime in two steps in terms of compressibility. The compressibility curves for 7 and 28 days of curing essentially traced over the ones of the samples with $7 \%$ lime added in a single step.

The shear strength parameters (plotted for a vertical pressure interval of 20-100 kPa, carried out at the same conditions), are represented by a cohesion of $14 \mathrm{kPa}$ and a shear resistance angle of $35^{\circ}$. The double step of lime addition, if compared with the single supply of binder at the same initial $\mathrm{w}$ (natural water content), allowed for an evident increase in the cohesion (14 kPa instead of $2.5 \mathrm{kPa}-$ see Table 3), whereas it did not seem to appreciably influence the shear resistance angle. As for the other specimens prepared starting from $\mathrm{w}_{\mathrm{Nat}}$, the shape of the stress-displacement curve is that typical of normal consolidated soils.

\subsection{Applicability and Operative Possible Solutions}

Besides good results obtained for the mixture compacted close to the optimum water content, it is important to underline that at high water contents $(>90 \%)$, the hydraulic and compressive behavior were modified to a lesser extent by lime treatment, even if the shear resistance seems to be positively affected in terms of peak shear resistance angle.

A fractionated supply of lime did not guarantee an improvement to a sufficient extent to be a viable solution to re-use the material.

Moreover, laboratory mixing and compaction of the treated soil turned out to be difficult to carry out, resulting in practical workability issues.

In light of the previous considerations and given the very high value of the soil natural water content, in situ operations still remain an open challenge. The preliminary laboratory results suggest that prior drying of the natural soil is necessary. Considering the typical temperatures of the Finnish summer season $\left(15-20^{\circ} \mathrm{C}\right)$, these conditions could not allow for the drying of soil to a sufficient extent. However, clayey deposits similar to the one studied can also be found in Asian countries where thermal conditions are auspicious for the possible prior drying of soil.

One possibility for drying the soil is setting an on-site stabilization plant equipped with a mechanical dryer. The cost of the in situ operations will significantly increase and the work timing is contingent upon the time required to obtain the desired water content (as an example, a typical productivity of a stabilization plant is 300-600 tons/hour and rotary dryers can typically dry up to 40 tons/hour of soil).

Another possibility is a recently patented drying truck, equipped with a tiller, capable of drying the soil to a depth of $30 \mathrm{~cm}$, which is the typical thickness of soil layers in stabilization works. With this device, stabilization works can be performed by adding a preliminary phase to the common operative sequences.

Adding other stabilizing agents, such as cement, in addition to lime, can improve mechanical characteristics $[10,28]$. With reference to cement, its components require only hydration to ensure pozzolanic reactions development, cement hydration will consume further water in the system, giving lime the possibility to perform better in it. It is important to point out that, in some cases, the hydraulic conductivity for fine-grained soil can increase when using cement (e.g., Reference [29]), thus the draining capability could be maintained. Therefore, the selection of the technique and of the type 
of binder to be used depends on the engineering requirements of the specific earthworks (e.g., road embankments have opposite hydraulic requirements to those of waste landfill sidewalls).

In any case, an increase in costs is obviously envisaged but, for each situation, the advantages/disadvantages of the proportion should be assessed.

In the particular case of Finland, it is essential to take into account that foundation soils of the dry crust are currently disposed with very high transportations costs: 2 euro $/ \mathrm{km}$ for each soil truck plus fees at the landfill gate (in Helsinki 10 euro $/ \mathrm{m}^{3}$ ). The estimated annual amount of excavated soils in Finland is 20-30 million tons, that corresponds to 3.7-5.5 tons/capita [30]. In the city of Helsinki only, in the year 2009, about 0.6 million $\mathrm{m}^{3}$ of soils were excavated and $70 \%$ of them were landfilled due to their poor quality [31]. In addition, official statistics show that the amount of waste generated by mining and quarrying activities is growing across recent years (56.9 Million tons in 2011, 62.8 Million tons in 2014, and 93.7 Million tons in 2016). Statistics also show that the volume of soil transport across the country is growing overall in recent years, contributing to an increased carbon footprint, as shown in Figure 12 (source: Statistics Finland https://www.stat.fi). Searching for methods and processes to re-use soils is therefore becoming a common objective and the present research can offer a preliminary contribution. After completion of the planned laboratory investigations, an in situ test pad will be carried out to assess a complete feasibility.

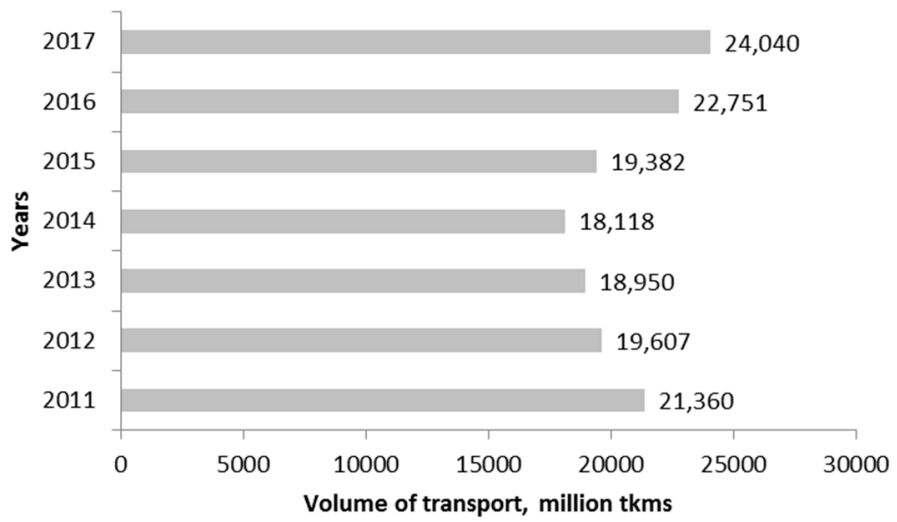

Figure 12. Volume of soil transport in Finland-source: Statistics Finland: https://www.stat.fi (Ton-kilometer describes the volume of transport and is obtained as a product of transported volume of goods in tons and length of transport journey in kilometers).

\section{Conclusions}

We have investigated the effects of lime addition on a soft, sensitive, reconstituted Finnish clay by laboratory testing as a preliminary evaluation of possible improvement of the clay geotechnical characteristics.

We selected a quicklime content of $7 \%$ with the main aim of significantly reducing the high natural water content of the clay $(110 \%)$. With such a percentage, the clay lost its sensitive behavior since the soil consistency was maintained after remolding and testing.

The improvement of mechanical characteristics of the compacted lime-treated clay resulted as being strongly influenced by the clay water content.

In the range of water contents of $10 \%$ to $40 \%$, corresponding to dry density values almost constant and very close to the maximum one, pozzolanic reactions, detected in the samples after just 2 days of curing, allow great reduction in compressibility and increase in both cohesion and peak shear angle, with respect to the natural soil reconstituted by compaction. Further significant improvements were found to occur with curing time. With reference to the hydraulic behavior, the lime addition and the consequent aggregation of particles resulted in an open microstructure with hydraulic conductivity values higher than those of the low-permeable compacted natural clay, in particular, for $\mathrm{w}=35 \%$, the hydraulic conductivity was 2 orders of magnitude greater than the corresponding untreated sample. 
The growth of the detected gel fibers of the pozzolanic products caused a significant reduction in the $\mathrm{k}$ values with curing time.

Lime addition to the clay at compaction water contents close to the natural one $(90 \%-130 \%)$ resulted to improve the mechanical characteristics to a lesser extent. In particular, we found no significant improvement in terms of compressibility and a poor increase in the shear strength. Lime addition did not significantly influence the hydraulic conductivity and resulted to not appreciably decrease with curing. A fractionated lime supply did not significantly improve the mechanical performance.

The results of this research demonstrate that re-using sensitive clays, typically of high-water contents, by lime addition requires a preliminary drying process. Different drying procedures can be adopted (as proposed in the paper) depending on the specific site conditions, which are still economically convenient in comparison with the costs of the only alternative solution of disposing sensitive clays in waste landfills.

Author Contributions: Conceptualization, M.D.S. and B.D.B.; methodology, M.D.S.; validation, E.F.; investigation, M.D.S.; data curation, M.D.S. and E.F.; writing—original draft preparation, M.D.S., B.D.B., and E.F.; writing-review and editing, E.F. and T.L.; supervision, E.F. and T.L. All authors have read and agreed to the published version of the manuscript.

Funding: This research received no external funding.

Acknowledgments: The authors thank the former students Flavio Giorgetti and Federica Levantesi for their cooperation in the experimental laboratory activities.

Conflicts of Interest: The authors declare no conflict of interest.

\section{References}

1. Torrance, J.K. A laboratory investigation of the effect of leaching on the compressibility and shear strength of Norwegian marine clays. In Norwegian Geotechnical Institute Publication; Norwegian Geotechnical Institute: Oslo, Norway, 1974; p. 104.

2. Rosenqvist, I.T. Considerations on the sensitivity of Norwegian quick-clays. Geotechnique 1953, 3, $195-200$. [CrossRef]

3. Bjerrum, L. Geotechnical properties of Norwegian marine clays. Géotechnique 1954, 4, 49-69. [CrossRef]

4. Rankka, K.; Andersson-Sköld, Y.; Hultén, C.; Larsson, R.; Leroux, V.; Dahlin, T. Quick Clay in Sweden; Technical Report No. 65; Swedish Geotechnical Institute: Linköping, Sweden, 2004; p. 137.

5. Länsivaara, T. A Study of the Mechanical Behavior of Soft Clay. Ph.D. Dissertation, Norwegian University of Science and Technology, Trondheim, Norway, 1999.

6. D'Ignazio, M.; Lunne, T.; Andersen, K.H.; Yang, S.; Di Buò, B.; Länsivaara, T. Estimation of preconsolidation stress of clays from piezocone by means of high-quality calibration data. AIMS Geosci. 2019, 5, 104-116.

7. Di Buò, B. Evaluation of the Preconsolidation Stress and Deformation Characteristics of Finnish Clays based on Piezocone Testing. Ph.D. Dissertation, Tampere University, Tampere, Finland, 2020; 186p.

8. Gardemeister, R. On Engineering-Geological Properties of Fine-Grained Sediments in Finland. Ph.D. Dissertation, University of Turku, Turku, Finland, 1975; 91p.

9. Greaves, H.M. An introduction to lime stabilization. In Lime Stabilisation; Roger, C.D.F., Glendinning, S., Dixon, N., Eds.; Thomas Telford: London, UK, 1996; pp. 5-12.

10. Winterkorn, H.F.; Pamukcu, S. Soil stabilization and grouting. In Foundation Engineering Handbook; Hsai-Yang, F., Ed.; Van Nostrand Reinhold: New York, NY, USA, 1991; pp. 317-378.

11. Transportation Research Board State of the Art Report 5: Lime Stabilization-Reactions, Properties, Design and Construction; Transportation Research Board: Washington, DC, USA, 1987; pp. 1-59.

12. Beetham, P.; Dijkstra, T.; Dixon, N.; Fleming, P.; Hutchinson, R.; Bateman, J. Lime stabilisation for earthworks: A UK perspective. ICE Proc. Ground Improv. 2014, 168, 81-95. [CrossRef]

13. Di Sante, M.; Fratalocchi, E.; Mazzieri, F.; Pasqualini, E. Time of reaction in a lime treated clayey soil and influence of curing conditions on its microstructure and behaviour. Appl. Clay Sci. 2014, 99, 100-109. [CrossRef]

14. De Brito Galvão, T.C.; Elsharief, A.; Simões, F. Effects of lime on permeability and compressibility of two tropical residual soils. J. Environ. Eng. 2004, 130, 881-885. [CrossRef] 
15. Consoli, N.C.; Lopes, L.S., Jr.; Heineck, K.S. Key parameters for the strength control of lime stabilized soils. J. Mat. Civ. Eng. 2009, 21, 210-216. [CrossRef]

16. Barker, J.E.; Rogers, C.D.F.; Boardman, D.I. Ion migration associated with lime piles: A review. Proc. Inst Civ. Eng. Ground Improv. 2007, 11, 87-98. [CrossRef]

17. Di Sante, M.; Fratalocchi, E.; Mazzieri, F. Effects of variation in compaction water content on geotechnical properties of lime-treated clayey soil. Procedia Eng. 2016, 158, 63-68. [CrossRef]

18. Fratalocchi, E.; Bellezza, I.; Di Sante, M.; Pasqualini, E. Mix-design, construction and controls of lime stabilized embankments. In Proceedings of the 17th International Conference on Soil Mechanics and Geotechnical Engineering, Alexandria, Egypt, 5-9 October 2009; Volume 3, pp. 2248-2251.

19. Di Sante, M. The Contribution of Microstructural Investigation to the Study of Lime-Treated Soils. In Proceedings of the 1st International Workshop on Metrology for Geotechnics, IMEKO TC-4, Benevento, Italy, 17-18 March 2016; pp. 16-21.

20. D'Ignazio, M.; Di Buò, B.; Länsivaara, T. A study on the behaviour of the weathered crust in the Perniö failure test. In Proceedings of the XVI European Conference on Soil Mechanics and Geotechnical Engineering, XVI ECSMGE, Edinburgh, Scotland, UK, 13-17 September 2015; ICE Publishing: London, UK, 2015; pp. 3639-3644.

21. GLO-85 Suomen Geoteknillinen Yhdistys Ry SGY. GLO-85 Geotekniset Laboratorioohjeet, 1. Luokituskokeet, Suomen Geoteknillinen Yhdistys Ry Ja Rakentajain Kustannus Oy. 1985. Available online: https:// books.google.it/books/about/Glo_85.html?id=vvXquAAACAAJ\&redir_esc=y (accessed on 1 May 2020). (In Finnish).

22. Hansbo, S. A new approach to the determination of the shear strength of clays by the fall-cone test. Proc. Roy. SGI 1957, 14, 7-48.

23. Koumoto, T.; Houlsby, G.T. Theory and practice of the fall cone test. Geotechnique 2001, 51, 701-712. [CrossRef]

24. Di Sante, M. On the compaction characteristics of soil-lime mixtures. Geotech. Geol. Eng. 2020, 38, 2335-2344. [CrossRef]

25. Schwarzer, K.; Ricklefs, K.; Bartholomä, A.; Zeiler, M. Geological development of the North Sea and the Baltic sea. In Die Küste, 74 ICCE; Kuratorium für Forschung im Küsteningenieurwesen: Hamburg, Germany, 2008; pp. 1-17.

26. Di Sante, M. Deepening on the Behavior of Soil-Lime Mixtures (Approfondimenti sul comportamento delle miscele terreno-calce). Ph.D. Dissertation, Università Politecnica delle Marche, Ancona, Italy, 2010; 226p. (In Italian).

27. Wild, S.; Arabi, M.; Rowlands, G.O. Relation between pore size distribution, permeability and cementitious gel formation in cured clay-lime systems. Mat. Sci. Technol. 1987, 3, 1005-1011. [CrossRef]

28. Bhattacharia, S.; Bhatty, J.I.; Todres, H.A. Stabilization of Clay Soils by Portland Cement or Lime-A Critical Review of Literature; PCA R\&D Serial No. 2066; Portland Cement Association: Skokie, IL, USA, 2003.

29. Bellezza, I.; Fratalocchi, E. Effectiveness of cement on hydraulic conductivity of compacted soil-cement mixtures. ICE Proc. Ground Improv. 2006, 10, 77-90. [CrossRef]

30. Magnusson, S.; Lundberg, K.; Svedberg, B.; Knutsson, S. Sustainable management of excavated soil and rock in urban areas-A literature review. J. Clean. Prod. 2015, 93, 18-25. [CrossRef]

31. LIFE Project n. LIFE09 ENV/FI/000575. FINAL Report: Sustainable mEthods and Processes to Convert Abandoned Low Quality Soils into Construction Materials. 2015, pp. 1-52. Available online: http: //projektit.ramboll.fi/life/absoils/index_eng.htm (accessed on 1 May 2020).

(C) 2020 by the authors. Licensee MDPI, Basel, Switzerland. This article is an open access article distributed under the terms and conditions of the Creative Commons Attribution (CC BY) license (http://creativecommons.org/licenses/by/4.0/). 